\title{
Effect of exercise training on insulin sensitivity, hyperinsulinemia and ectopic fat in black South African women: a randomized controlled trial
}

\author{
Melony C Fortuin-de Smidtt,2, Amy E Mendham ${ }^{1,2}$, Jon Hauksson ${ }^{3}$, Olah Hakim ${ }^{4}$, Darko Stefanovski', \\ Louise Clamp' ${ }^{1}$, Lindokuhle Phiri', Jeroen Swart ${ }^{1}$, Louise M Goff ${ }^{4}$, Lisa K Micklesfield ${ }^{1,6}$, Steven E Kahn ${ }^{7}$, \\ Tommy Olsson ${ }^{8}$ and Julia H Goedecke ${ }^{1,2}$
}

${ }^{1}$ Division of Exercise Science and Sports Medicine, Department of Human Biology, University of Cape Town, Cape Town, South Africa, ${ }^{2}$ Non-Communicable Diseases Research Unit, South African Medical Council, Tygerberg, South Africa, ${ }^{3}$ Department of Radiation Sciences, Radiation Physics and Biomedical Engineering, Umeå University, Umeå, Sweden, ${ }^{4}$ Department of Diabetes, School of Life Course Sciences, Faculty of Life Sciences \& Medicine, King's College London, London, UK, ${ }^{5}$ Department of Clinical Studies, New Bolton Center, University of Pennsylvania, School of Veterinary Medicine, Kennett Square, Pennsylvania, USA, ${ }^{6}$ MRC/Wits Developmental Pathways for Health Research Unit, Faculty of Health Sciences, University of the Witwatersrand, Johannesburg, South Africa, ${ }^{7}$ Division of Metabolism, Endocrinology and Nutrition, Department of Medicine, Veterans Affairs Puget Sound Health Care System and University of Washington, Seattle, Washington, USA, and ${ }^{8}$ Department of Public Health and Clinical Medicine, Umeå University, Umeå, Sweden

Correspondence should be addressed to M C Fortuin-de Smidt Email mcfortuindesmidt@gmail. com

\begin{abstract}
Objective: We investigated the effects of a 12-week exercise intervention on insulin sensitivity $\left(\mathrm{S}_{1}\right)$ and hyperinsulinemia and associated changes in regional and ectopic fat.

Research design and methods: Healthy, black South African women with obesity (mean age $23 \pm 3.5$ years) and of isiXhosa ancestry were randomised into a 12-week aerobic and resistance exercise training group $(n=23)$ and a no exercise group (control, $n=22$ ). Pre and post-intervention testing included assessment of $S_{1}$, insulin response to glucose (AIRg), insulin secretion rate (ISR), hepatic insulin extraction $\left(\mathrm{FE}_{\mathrm{L}}\right)$ and disposition index (DI) $\left(\mathrm{AIRg} \times \mathrm{S}_{\mathrm{I}}\right)$ (frequently sampled i.v. glucose tolerance test); fat mass and regional adiposity (dual-energy X-ray absorptiometry); hepatic, pancreatic and skeletal muscle fat content and abdominal s.c. and visceral adipose tissue volumes (MRI). Results: Exercise training increased $\mathrm{VO}_{2 \text { peak }}$ (mean \pm S.D.: $24.9 \pm 2.42$ to $\left.27.6 \pm 3.39 \mathrm{~mL} / \mathrm{kg} / \mathrm{min}, P<0.001\right), \mathrm{S}_{1}(2.0(1.2-$ 2.8 ) to $\left.2.2(1.5-3.7)(\mathrm{mU} / \mathrm{l})^{-1} \mathrm{~min}^{-1}, P=0.005\right)$ and $\mathrm{DI}$ (median (interquartile range): $6.1(3.6-7.1)$ to $6.5(5.6-9.2) \times 10^{3}$ arbitrary units, $P=0.028)$, and decreased gynoid fat mass $(18.5 \pm 1.7$ to $18.2 \pm 1.6 \%, P<0.001)$ and body weight $(84.1 \pm 8.7$ to $83.3 \pm .9 .7 \mathrm{~kg}, P=0.038)$. None of these changes were observed in the control group, but body weight increased $(P=0.030)$. AIRg, ISR and FE $\mathrm{L}^{\prime}$ VAT, SAT and ectopic fat were unaltered after exercise training. The increase in $S_{1}$ and DI were not associated with changes in regional or ectopic fat.

Conclusion: Exercise training increased $\mathrm{S}_{1}$ independent from changes in hyperinsulinemia and ectopic fat, suggesting that ectopic fat might not be a principal determinant of insulin resistance in this cohort.
\end{abstract}




\section{Introduction}

Insulin resistance and hyperinsulinemia are more frequently found in black African women compared to white women (1). However, the mechanisms that underlie the high prevalence of insulin resistance and hyperinsulinemia and type 2 diabetes in black South African (SA) women have not been fully elucidated.

Notably, black African women exhibit a unique phenotype that contradicts the established determinants of insulin resistance typically shown in white populations. Compared to their white counterparts, black African women have less visceral adipose tissue (VAT) (2), a proven determinant of insulin resistance (3), and more peripheral s.c. adipose tissue (SAT) (2), typically regarded as protective (4). Similarly, black African women have less hepatic fat and equivalent i.m. fat compared to their white counterparts (5). Hyperinsulinemia found in black Africans has been ascribed to low insulin sensitivity $\left(\mathrm{S}_{\mathrm{I}}\right)$, with low hepatic insulin extraction and/or high insulin secretion rate (ISR) (6). Studies in black African populations have reported that low hepatic insulin extraction was not associated with hepatic fat $(7,8)$, while insulin response/ $\beta$ cell function was positively associated with pancreatic fat $(9,10)$. However, these were cross-sectional studies from which we cannot infer causality.

Exercise can decrease the risk for developing type 2 diabetes (11), most likely through its ability to improve $S_{\text {I }}$ (12). In addition, exercise training has been shown to reduce the insulin response, after an oral glucose load, in healthy adults with obesity (13), although this response may be modified by the baseline insulin secretory capacity (14). Further, exercise training may also reduce skeletal muscle (15), hepatic (16) and pancreatic fat (17), which may explain exercise-induced alterations in $S_{I}$ and hyperinsulinemia. However, an exercise-intervention study that evaluates the chronic training effects on $S_{I}$ and hyperinsulinemia, as well as on skeletal muscle, hepatic and pancreatic fat, has not been completed in a black African population who present with a unique phenotype. Accordingly, the current study hypothesizes that exercise training would increase $\mathrm{S}_{\mathrm{I}}$ and decrease hyperinsulinemia in black SA women with obesity, which would be associated with favorable changes in ectopic and regional fat distribution.

\section{Methods}

The study design and detailed methods have been published previously (18) and are described in brief below.
The CONSORT diagram for the work described here is provided in Fig. 1.

\section{Study design and participants}

In this randomized controlled exercise intervention, black SA women were recruited from a low socioeconomic community in Cape Town. Inclusion criteria were: obesity (BMI 30-40 kg/m²), both parents of isiXhosa descent (self-reported), 20-35 years old, stable weight ( $<5 \mathrm{~kg}$ change in weight in the last 6 months), using injectable contraception (depot medroxyprogesterone acetate, $400 \mathrm{mg}$ ) for a minimum of 2 months prior to testing. Participants were excluded if they had any known diseases (e.g. HIV, hypertension, diabetes (random blood glucose $>11.1 \mathrm{mmol} / \mathrm{L}$, HbA1c $>6.5 \%)$ ), were pregnant or lactating, smoking or had any other orthopaedic or medical problems that prevented or restricted exercise participation. University of Cape Town Human Research Ethics Committee provided ethical permission. The trial was registered in the Pan African Clinical Trial Registry (PACTR201711002789113). Written informed consent was obtained prior to screening and testing procedures. Eligible participants were blocked randomized (2-4 participants) into an exercise $(n=23)$ and control group $(n=22)$. Three women in the exercise group and seven in the control group did not complete the trial, as described previously (18).

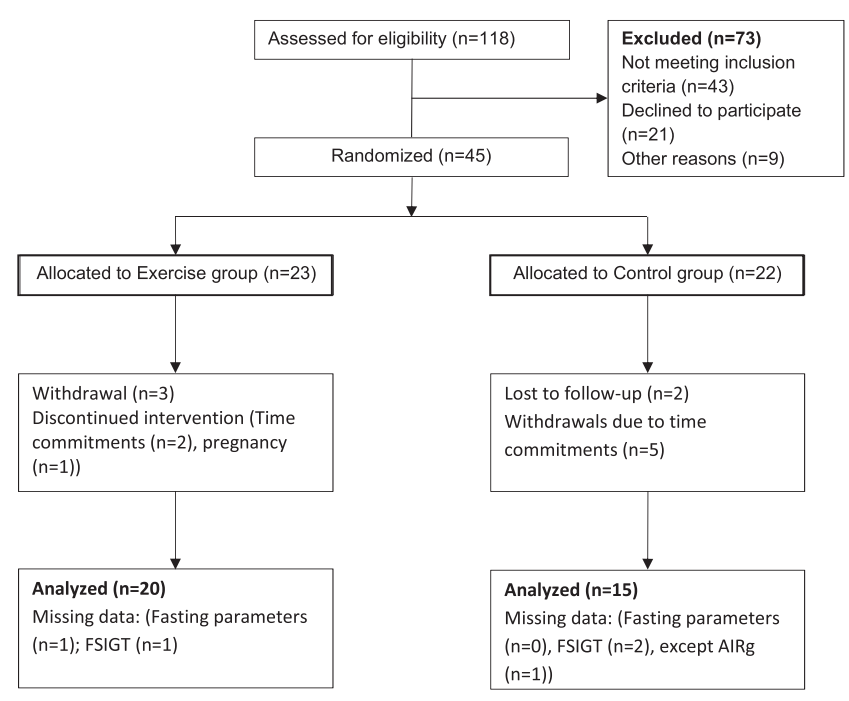

Figure 1

CONSORT participant flow diagram (adapted from Goedecke et al. (18)). 


\section{Exercise intervention}

The exercise group participated in 12-weeks of aerobic and resistance training, 40-60 $\mathrm{min}, 4$ days per week (Table 1) and every session was supervised by a qualified clinical exercise specialist. The intervention included aerobic-based exercises (dance, running, skipping and stepping) performed at a moderate-vigorous intensity (75-85\% peak heart rate, $\mathrm{HR}_{\text {peak }}$ ) and progressive (body weight, bands and free weights) strengthening exercises to achieve a prescribed intensity of $60-70 \% \mathrm{HR}_{\text {peak }}$ (Table 1). Based on the results of focus group discussions conducted in black SA women (19), the intervention utilized a combination of exercises to ensure greater enjoyment and adherence.

A heart rate monitor (Polar Electro, Kempele, Finland) was used to ensure participants achieved the desired exercise intensity and attendance was recorded for each session. The control and exercise groups were instructed to continue with habitual activity and dietary patterns.

\section{Anthropometrics and body fat distribution}

Anthropometric measurements included weight, height, hip and waist circumferences. Whole body composition was measured by dual-energy X-ray absorptiometry (DXA; Discovery-W®, software version 12.7.3.7; Hologic, Bedford, MA, USA), in the morning after an overnight fast, for the analyses of total body (whole body minus head) fat mass and fat-free soft tissue mass, as well as trunk, leg, android and gynoid fat mass (20).

\section{Cardiorespiratory fitness}

Peak oxygen consumption $\left(\mathrm{VO}_{2 \text { peak }}\right)$ was measured using a walking treadmill-based (C, Quasar LE500CE, HP Cosmos, Nussdorf-Traunstein, Germany), graded exercise test designed for sedentary participants that are not familiar with gym-based equipment. The test started at $3 \mathrm{~km} / \mathrm{h}$ at $2 \%$ gradient and the gradient was increased by $2 \%$ every 2 min until a gradient of $16 \%$ were reached. Thereafter, the speed and gradient were increased alternatively $(0.5$ $\mathrm{km} / \mathrm{h}$ and $1 \%$, respectively) to volitional exhaustion (21). $\mathrm{VO}_{\text {2peak }}$ was measured by indirect calorimetry (CPET, Cosmed, Rome, Italy) and heart rate was monitored continuously (Polar Electro Oy, Kempele, Finland) to determine $\mathrm{HR}_{\text {peak }}$. 


\section{Insulin secretion, insulin clearance and insulin sensitivity}

Prior to the testing day, participants slept overnight at the laboratory and consumed a standardized meal at 20:00 h (Energy: 2,456 kJ, 21 g protein (14\% energy), 49 g carbohydrate (33\% energy) and $32 \mathrm{~g}$ fat (48\% energy)), followed by an overnight fast (10-12 h). In the morning, fasting blood samples were drawn for measurement of HbA1c, insulin, glucose and C-peptide, and insulinmodified frequently sampled i.v. glucose tolerance test (FSIGT) was performed. Glucose (50\% dextrose; $11.4 \mathrm{~g} /$ $\mathrm{m}^{2} \times$ body surface area) was infused at 0 min over a 60 $s$ period followed at $20 \mathrm{~min}$ by an infusion of human insulin (0.02 unit/kg; NovoRapid, Novo Nordisk Limited) over 5 min at a constant rate. Thirty-three blood samples were drawn for the measurement of insulin, glucose and C-peptide at standardised time points over 240 min, following the start of glucose administration. Postintervention testing occurred $72 \mathrm{~h}$ following the last exercise training session.

\section{Mathematical modelling}

The minimal model of glucose kinetics was used to calculate: $S_{\mathrm{I}}$, glucose effectiveness $(\mathrm{Sg})$, the acute insulin response to glucose (AIRg), and disposition index $\left(\mathrm{DI}=\mathrm{S}_{\mathrm{I}} \times \mathrm{AIRg}\right)$ (22). A two-compartment model was used to determine the ISR using standard kinetic parameters taking into account obesity (23). The total area-undercurve (AUC) for glucose, insulin and C-peptide, derived from the FSIGT and ISR, was calculated using the trapezoidal rule. Hepatic and peripheral insulin clearance was determined as previously described (24). WinSAAM was used to estimate these model parameters (25). Hepatic insulin clearance can either be explained by a linear or a saturable model. Both models were run on all participants. The model with the lowest Akaike Information Criteria (26) was chosen as the preferred model. The linear model provided a single parameter $\left(\mathrm{FE}_{\mathrm{L}}\right)$ to explain hepatic insulin extraction (post-glucose load), compared to two parameters $\left(\mathrm{V}_{\max }\right.$ and $\left.\mathrm{K}_{\mathrm{m}}\right)$ provided by the saturable model. In order to compare $\mathrm{FE}_{\mathrm{L}}$, only participants in whom the linear model was preferred pre-and post-intervention were included in the analysis $(n=21)$.

\section{Ectopic fat}

A standardized meal (Energy: $2553 \mathrm{~kJ}$, protein: $20.9 \mathrm{~g}$; carbohydrates: $83.0 \mathrm{~g}$; fat: $22.2 \mathrm{~g}$ ) was consumed 2-4 $\mathrm{h}$ prior to ectopic fat determination. MRI was used to determine hepatic, pancreatic and skeletal muscle (soleus, tibialis anterior) fat content using a 3 Tesla whole-body human MRI scanner (MAGNETOM Skyra; Siemens Medical Solutions). A three-point Dixon volume interpolated breath-hold gradient recalled echo sequence were used: TR $3.97 \mathrm{~ms}$, TE1 $1.23 \mathrm{~ms}$, TE2 $2.46 \mathrm{~ms}$, flip angle 9 degrees, number of averages 1, bandwidth $1040 \mathrm{~Hz} / \mathrm{px}$, field of view $450 \times 366 \mathrm{~mm}$, matrix size $195 \times 320 \times 144$ and a slice thickness of $2 \mathrm{~mm}$. The three-point Dixon method has been validated before using a fat/water phantom and was found to be accurate and reproducible even at low levels of fat in liver, pancreas and skeletal muscle (27).

A MATLAB algorithm was used to separate the water and fat signals and to create a fat fraction map calculated as the fat signal over the sum of the water and fat signals. Region of interests (ROIs) were manually drawn using OsiriX (liver, muscle) and HOROS V 1.1.7 (pancreas, VAT, abdominal SAT). The precision of manual methods in fat quantification are not significantly different compared to semi-automated methods $(28,29)$. An ROI was drawn on seven consecutive slices of the right lobe of the liver, avoiding ducts and blood vessels, and over the largest cross-sectional area of soleus and tibialis anterior muscles, adapted from Machann et al. (30). The ROI included the intermuscular fat but excluded the fatty septa between muscles. Pancreatic fat was determined by drawing one circular $1 \mathrm{~cm}^{2}$ ROI in the head, body and tail of the pancreas. This method was used to avoid inclusion of VAT (31). Abdominal VAT and SAT volumes were determined by calculating the sum of the VAT and SAT areas from five images in a $15 \mathrm{~cm}$ region from the level of L1-5 and then multiplied by 3 (32). The above-mentioned methods were found to have high precision in previous studies (28, $29,33,34)$.

\section{Biochemical analyses}

HbA1c was analysed using HPLC (Meharini Diagnostics, Florence, Italy). Plasma glucose was measured using a colorimetric assay (Randox (Pty) Ltd, Gauteng, South Africa). Serum insulin and C-peptide were determined by an immunochemiluminometric assays (IMMULITE 1000 immunoassay system, Siemens Healthcare (Pty) Ltd, Midrand, South Africa). Pre- and post-intervention samples for a participant were run in the same assay. Coefficient of variation for assays ranged from 6 to $8.5 \%$. 


\section{Physical activity and dietary monitoring}

Energy expenditure of both groups was estimated using accelerometery (ActiGraph GTX3+, LLC, Pensacola, Florida), worn for $24 \mathrm{~h}$ a day over a 7-day period at baseline, 4, 8 and 12 weeks. Energy expenditure was compared between the exercise (non-exercise days) and the control group. Dietary intake was measured by a registered dietician using a 24-h dietary intake recall and a 3-day dietary record ( 2 weekdays and 1 weekend day) at baseline, 4 and 8 and 12 weeks.

\section{Statistical analysis}

Data was analysed using STATA 12.0 (College Station, TX, USA). Data were expressed as mean \pm S.D. or median and interquartile range (IQR) for normally and skewed data, respectively. The latter were transformed to achieve normality prior to mixed-model analysis in which the random and fixed effects referred to intersubject variability and differences between the groups, respectively. Fisher's least significant difference post hoc test was used when appropriate. Linear regression determined associations between changes in main outcomes and changes in predictors in the combined group and to check for group interactions. A $P$ value of $\leq 0.05$ was regarded as statistically significant. The sample size determination, based on the change in normalized glucose clearance determined by euglycemic hyperinsulinemic clamp (35), using a power of $80 \%$ and a significance level of $P<0.05$ was six participants per group. A per protocol analysis was performed on those with both pre- and post-intervention data available ( $n=15$ control and $n=20$ exercise group).

\section{Results}

\section{Exercise adherence and effect of exercise on cardiorespiratory fitness}

Mean exercise session attendance was 79\% (range $52-100 \%)$ at a mean intensity of $79.6 \pm 4.0 \% \mathrm{HR}_{\text {peak }}$. An improvement in cardiorespiratory fitness $\left(\mathrm{VO}_{2 \text { peak }}\right)$ was observed in the exercise group $(2077 \pm 211$ to $2278 \pm 231$ $\mathrm{mL} / \mathrm{min}, \quad P<0.001$ and $24.9 \pm 2.42$ to $27.6 \pm 3.39$ $\mathrm{mL} / \mathrm{kg} / \mathrm{min}, P<0.001$ ), while no change was observed in the control group $(2099 \pm 282$ to $2032 \pm 196$ $\mathrm{mL} / \mathrm{min}, \quad P=0.286$ and $23.9 \pm 2.97$ to $23.0 \pm 2.64$ $\mathrm{mL} / \mathrm{kg} / \mathrm{min}, P=0.309)$.

\section{Dietary and physical activity}

Energy intake, macronutrient composition of the diets, and total energy expenditure (non-exercise days in the exercise group) did not differ within or between groups at baseline, 4, 8 and 12 weeks (Supplementary Table 1, see section on supplementary materials given at the end of this article).

\section{Effect of exercise training on metabolic outcomes}

No differences in metabolic outcomes were observed between groups at baseline. Exercise training improved the AUC of glucose total (group $\times$ time $P=0.020$ ) (Supplementary Fig. 1). $S_{\mathrm{I}}$ improved in the exercise group (post hoc $P=0.005$ ), improving in 15 out of 19 participants, with no change in the control group (post hoc $P=0.711$ ) (Fig. 2). In contrast, the AUC for insulin and C-peptide did not change with exercise training (Supplementary Fig. 1). Accordingly, no changes were observed in AIRg (Fig. 2), ISR, hepatic insulin extraction and peripheral insulin clearance. As $S_{I}$ improved with no reciprocal change in AIRg, DI increased after exercise training (post hoc $P=0.028$ ) (Table 2).

\section{Effect of exercise training on body composition and body fat distribution and ectopic fat content}

A small but significant reduction in body weight was observed after exercise training (mean $\Delta-0.82 \mathrm{~kg}$, post hoc $P=0.038$ ), whereas the control group gained body weight (mean $\Delta+1.0 \mathrm{~kg}$, post hoc $P=0.030$ ) and abdominal SAT (mean $\Delta+285.5 \mathrm{~cm}^{3}$, post hoc $P=0.008$ ). While exercise training did not alter total fat mass, fat-free soft tissue
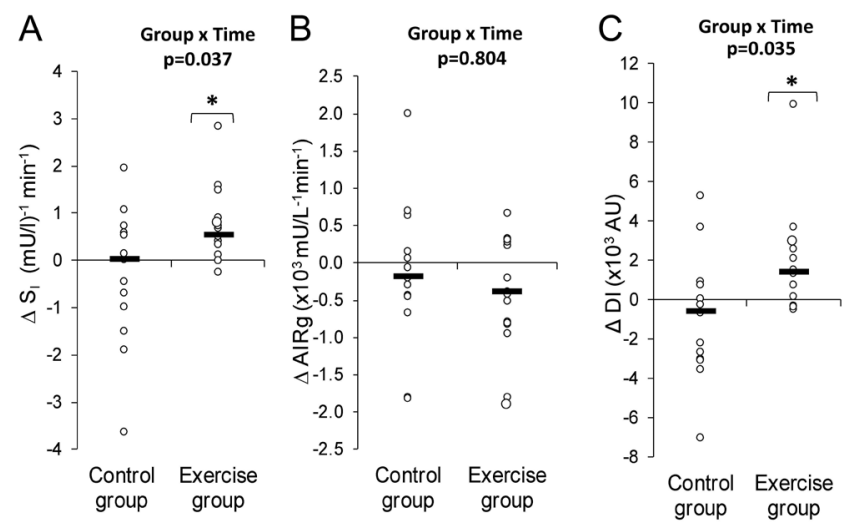

\section{Figure 2}

Changes in $(A)$ insulin sensitivity $\left(S_{1}\right),(B)$ acute insulin response to glucose $\left(A I R_{g}\right)$ and $(C)$ disposition index (DI) in the control and exercise groups. Thick black line - median, empty circles - individual changes. *Post hoc test $P \leq 0.05$. 


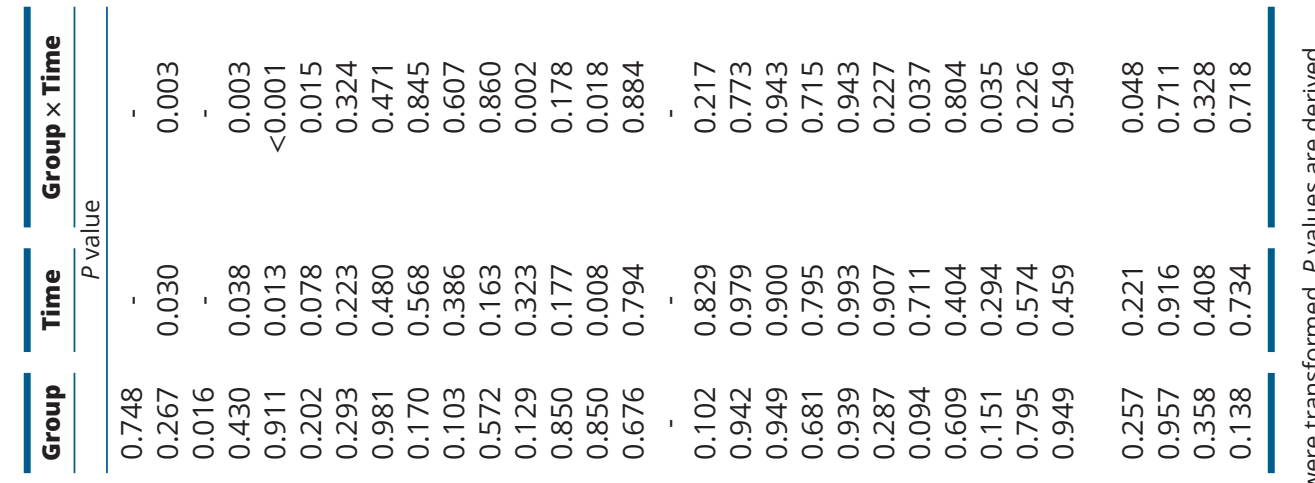


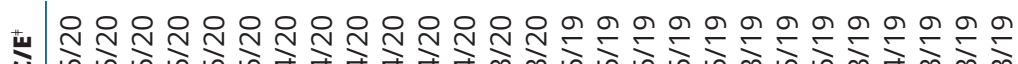

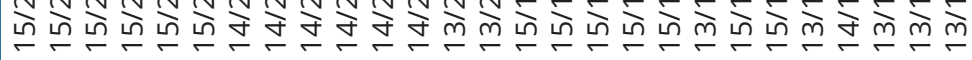

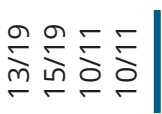

* * * $\quad$ m

बi m은

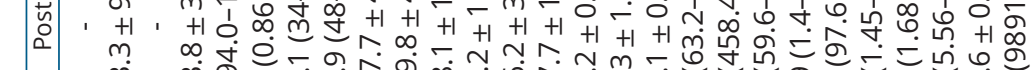

m m m

नूं

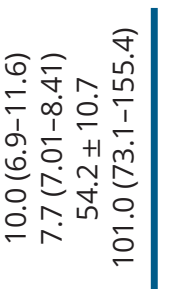

宛 向

d

¿

ㅁํㄹ

ก

崔

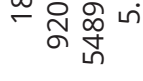

เก

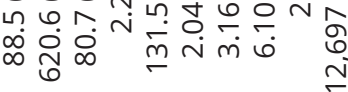

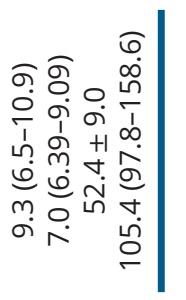

|

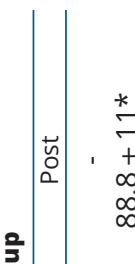

* * * ํำ

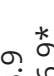

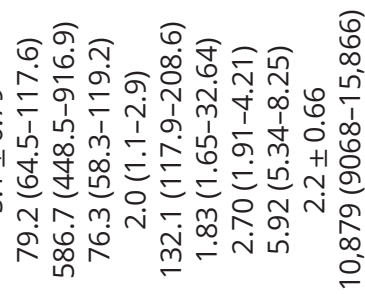

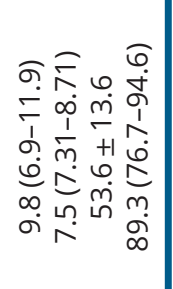

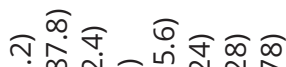

ํํำ

กิ่

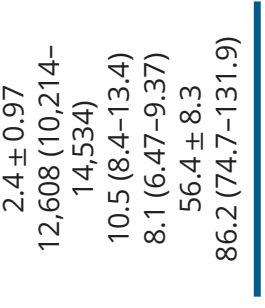

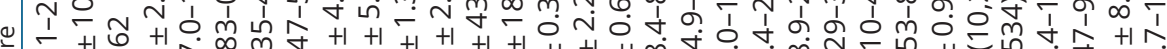

¿

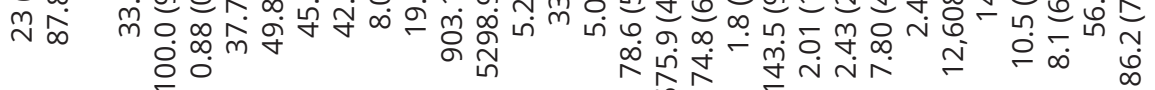

$\frac{\sqrt{\frac{0}{0}}}{\frac{0}{0}}$

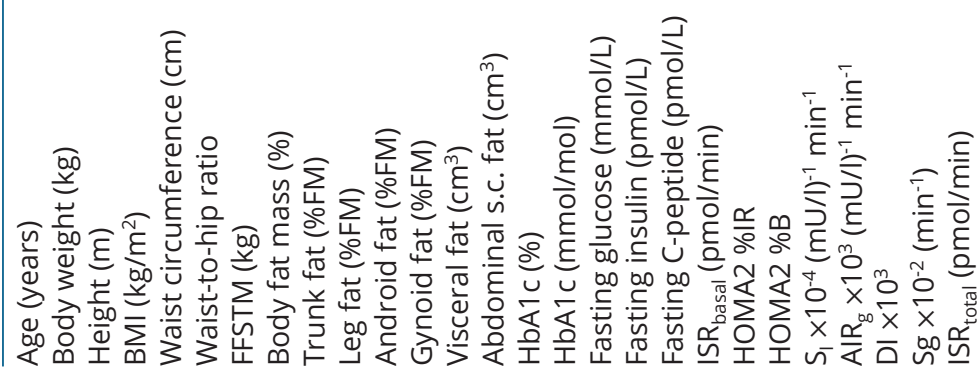

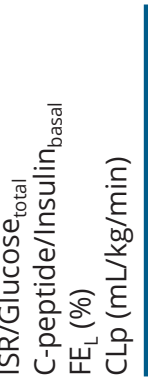

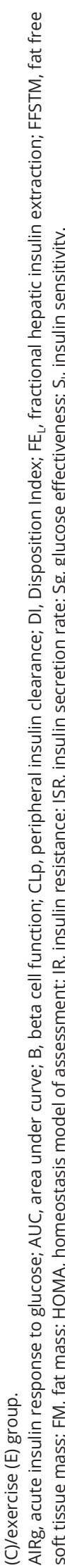



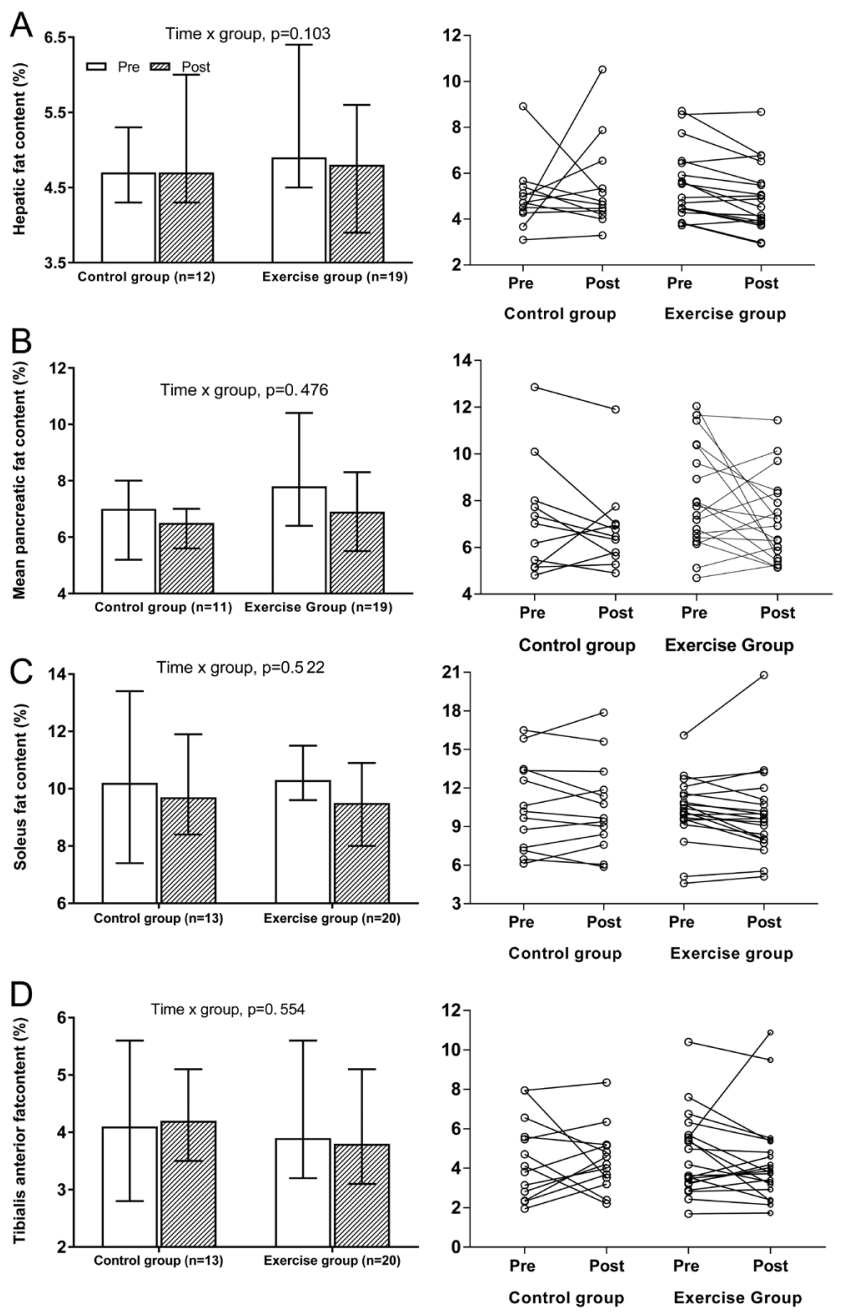

\section{Figure 3}

Individual changes from pre- to post-exercise training in (A) hepatic, (B) pancreatic, (C) soleus and (D) tibialis anterior fat in control and exercise group.

mass, abdominal SAT and VAT, there was a significant decrease in gynoid fat mass $(\%)(P<0.001)$ in the exercise group only. After exercise training the pancreatic (7.8 (6.4$10.4) \%$ to $6.9(5.5-8.3) \%)$, hepatic (4.9 (4.5-6.4)\% to 4.8 $(3.9-5.6) \%)$, soleus $(10.3(9.5-11.5) \%$ to $9.6(8.0-10.9) \%)$ and tibialis anterior (3.9 (3.2-5.6)\% to $3.8(3.1-5.1) \%)$ fat, remained unaltered (Fig. 3 and Table 2).

\section{Associations between changes in DI, $S_{1}$ AIRg, ISR, insulin clearance and changes in body composition, body fat distribution, ectopic fat and $\mathrm{VO}_{2 \text { peak }}$}

Even though body fat distribution, except gynoid fat mass (\%), and ectopic fat did not change significantly after exercise training, the variability in the participants' responses allow us to assess the associations between the changes in metabolic outcomes and fat depots in response to the intervention. The exercise-induced increases in $\mathrm{S}_{\mathrm{I}}$ and DI were not associated with changes in body fat mass (\%), gynoid fat mass (\%), android fat mass (\%) and ectopic fat (data not shown). Nevertheless, only in the control group (significant interaction by intervention group), significant associations were observed between changes in $S_{I}$ and changes in trunk fat mass $(\%)(\beta-0.628, P<0.001)$ and leg fat mass (\%) ( $\beta$ 0.745, $P=0.002)$. Further, in the combined group (control and exercise groups; no interaction by intervention group), an increase in $S_{I}$ was associated with a reduction in VAT $(\beta-0.002, P=0.035)$ and an increase in DI was associated with a reduction in trunk fat mass (\%) $(\beta-842.7, P=0.036)$. Similarly, an increase in $I_{\text {total }}$ was associated with a reduction in trunk fat mass (\%) $(\beta$ $-1237.8, P=0.020)$, but no significant associations occurred with changes in ectopic fat either in the combined or in the exercise or control groups (data not shown). No significant associations were observed between changes in AIRg and insulin clearance and changes in body fat distribution and ectopic fat (data not shown). No significant associations were found between any of the metabolic outcomes and change in $\mathrm{VO}_{2 \text { peak }}$ (data not shown).

\section{Discussion}

For the first time, we comprehensively explored the effects of exercise training on $\mathrm{S}_{\mathrm{I}}$, and hyperinsulinemia, as well as on pancreatic, hepatic and muscle fat and body fat distribution in black African women with obesity, who frequently present with low $S_{I}$ and hyperinsulinemia (36, $37)$. We showed that after 12 weeks of exercise training, $\mathrm{S}_{\mathrm{I}}$ increased but without any change in AIRg, and thus, showed a corresponding increase in DI. Further, the ISR and insulin clearance did not change after exercise training, which could explain the lack of change in AIRg. There were no changes in central or ectopic fat depots, but gynoid fat mass (\%) decreased after exercise training. Notably, body fat distribution or ectopic fat changes were unrelated to the increase in $\mathrm{S}_{\mathrm{I}}$ or DI.

Evidence on the effect of exercise training on $\mathrm{S}_{\mathrm{I}}$ in black African populations are scarce. We, therefore, add to the literature by showing that exercise training improved $S_{I}$ in black South African women with obesity. However, the improvement of $6 \%$ in $\mathrm{S}_{\mathrm{I}}$ in our study is modest compared to earlier studies conducted in older African American women with obesity (58\%) (38) and African American 
adolescents with obesity (37\%) (39). This discrepancy may be explained by the acute exercise effect on $S_{I}$ which may last up to $72 \mathrm{~h}$ after a bout of exercise (40). The improvement in $\mathrm{S}_{\mathrm{I}}$ in the earlier studies was demonstrated 14-18 $\mathrm{h}$ and $24-48 \mathrm{~h}$, respectively $(38,39)$, after the last exercise session, compared to $72 \mathrm{~h}$ in our study. Another point to consider is the intensity of the exercise training since greater improvements in $\mathrm{S}_{\mathrm{I}}$ have been observed with high intensity interval training compared to moderate intensity exercise training (41). Our study was performed at a moderate-high intensity (60-80\% of $\mathrm{VO}_{2 \text { peak }}$ ) and used a combination of aerobic and strength training that has shown greater improvements in $\mathrm{S}_{\mathrm{I}}$ compared to either of these modalities alone (42).

Notably, we showed improvements in $S_{I}$ and the $\mathrm{VO}_{2 \text { peak }}$, despite minimal weight loss $(\sim 1 \mathrm{~kg})$. Similarly, improvements in both $\mathrm{S}_{\mathrm{I}}$ and $\mathrm{VO}_{\text {2peak }}$ were observed in adults without obesity after 16 weeks of aerobic exercise training with marginal weight loss $(0.5 \mathrm{~kg})$, associated with augmented muscle mitochondrial enzyme activity and mitochondrial biogenesis gene expression, as well as increased GLUT4 mRNA and protein expression (43). Further, 12 weeks of moderate-intensity exercise training in men with obesity, improved both $\mathrm{S}_{\mathrm{I}}$ and $\mathrm{VO}_{2 \text { peak }}$ without weight loss with a contemporaneous reduction in systemic and skeletal muscle oxidative stress markers and an increased skeletal muscle antioxidant capacity (44). Therefore, both mitochondrial-related factors and the oxidative stress:antioxidant balance may be implicated in the improvement of $S_{I}$ in our study. Further, the improvement of $S_{I}$ in our study was not related to changes in central fat depots, since both VAT and abdominal SAT were unaltered after exercise training. In line with this, an increase in $S_{I}$ was reported in overweight men after 6 weeks of exercise training with no concurrent reduction in VAT, but rather a reduction in fatty acid availability (45). The exercise-induced increase in $\mathrm{S}_{\mathrm{I}}$ in our study may therefore be due to cellular changes within muscle and adipose tissue. Further research is required to address these hypotheses.

The lack of change in the ISR and hepatic insulin extraction was unexpected. Other exercise training studies have shown a reduction in stimulated insulin response $(46,47)$ or insulin secretion (17) in those with normal glucose tolerance. However, these studies were conducted in predominantly white older men and women known to have relatively lower baseline plasma insulin levels than those of black African ancestry. Notably, exerciseintervention studies that demonstrated reductions in AIRg either showed reduced body fat mass $(46,48,49)$ or reduced VAT (47). While no change in AIRg was observed in those with no significant change in VAT (47). These studies highlight a possible bi-directional relationship between hyperinsulinemia and body fat mass. In support, we showed in the combined group that a reduction in DI and $\mathrm{ISR}_{\text {total }}$ was associated with a reduction in trunk fat mass (\%). While our 12-week exercise training program was unable to reduce hyperinsulinemia, despite increasing $\mathrm{S}_{\mathrm{I}}$ it produced a modest decrease in body weight $(<1$ $\mathrm{kg}$ ) with no changes in central and ectopic fat depots. Notably, even in lifestyle intervention studies such as the Diabetes Prevention Program that included both exercise training and dietary changes, black African American women demonstrated smaller reductions in body weight compared to Black African American men and White and Hispanic men and women (50). It is possible that the inability to show greater exercise-induced changes in black women could be due to higher fasting and/or stimulated insulin levels. Insulin is a potent suppressor of lipolysis in adipose tissue and therefore limits free fatty acid mobilization (51). Even during exercise, excess insulin impedes the $\beta$-adrenergic stimulation of lipolysis (51). Thus, longer exercise training duration in combination with a dietary intervention, most likely a low carbohydrate and low glycemic diet (52), might be required to reduce hyperinsulinemia and consequently fat mass and central/ectopic depots in women with obesity and of black African ancestry.

A hyperbolic association has been described between AIRg and $S_{I}$, where a reduction in $S_{I}$ results in compensatory increase in AIRg to maintain euglycemia (53). The stabilization point in black Africans occurs to the extreme left of the hyperbola (54), so that even a small increase in $S_{I}$ could result in a reduction in AIRg. However, no change in AIRg was found in our study after exercise training. This might suggest that a high AIRg can occur independent from a low $S_{I}$ and that perhaps a low $\mathrm{S}_{\mathrm{I}}$, found in black African population might not be the primary stimulus of a high AIRg. In support, a higher AIRg was found in normal-weight black compared to white children, matched for $\mathrm{S}_{\mathrm{I}}(55)$. Furthermore, in vitro studies have shown that hyperinsulinemia may directly impact $S_{\text {I }}$ through its effect on the insulin receptors (56) and/or indirectly through obesity-related sequelae (57). However, while exercise training can increase $S_{I}$ independent to a loss in fat mass (44), a reduction in hyperinsulinemia may be required for sustained elevations in $\mathrm{S}_{\mathrm{I}}$.

Lastly, the significant reduction in gynoid fat mass (\%) after exercise training is of major interest. We have previously reported lower adipogenesis (58) and higher 
inflammation (59), fibrosis and hypoxia (60) in the gluteal fat depots of black SA women, compared to white women. Accordingly, the reduction in gynoid fat mass may have major beneficial long-term metabolic effects.

Our study has several strengths, including the randomized controlled design, using objective measures to ensure exercise intensity was maintained over the 12 -week period. Monitoring of diet and habitual physical activity limited bias from these lifestyle behaviors on our observed findings. A limitation of our study is that we could not isolate the effect of exercise training on hepatic or adipose tissue insulin resistance because the FSIGT gives a measure of whole-body $\mathrm{S}_{\mathrm{I}}$. In addition, this study was conducted in black SA women and might not be generalizable to other ethnic groups or men.

In conclusion, we have demonstrated that in women known to present with hyperinsulinemia, 12 weeks of combined aerobic and resistance training increased $S_{\text {I }}$ without concomitant changes in insulin secretion/ clearance or central and ectopic fat depots. These findings suggest that ectopic fat might not be the primary determinant of insulin resistance in this cohort, rather intrinsic factors in the muscle and adipose tissue may explain the exercise-induced changes in $\mathrm{S}_{\mathrm{I}}$. Moreover, the greater insulin response found more frequently in black compared to white women, might not solely occur in compensation of a low $\mathrm{S}_{\mathrm{I}}$. Further, we found a reduction in gynoid fat that may have long-term beneficial effects in this study population.

\section{Supplementary materials}

This is linked to the online version of the paper at https://doi.org/10.1530/ EJE-19-0957.

\section{Declaration of interest}

The authors declare that there is no conflict of interest that could be perceived as prejudicing the impartiality of this study.

\section{Funding}

This study was funded by the National Research Foundation of South Africa (NRF), Competitive Programme for Rated Researchers (Grant no: 93,577), the NRF/STINT Sweden/South Africa Research Collaboration Programme (UID: 106,784), the South African Medical Research Council (SAMRC). MF is a recipient of a South African Medical Research Council Clinician Researcher PhD Scholarship Programme. The content hereof is the sole responsibility of the authors and does not necessarily represent the official views of the SAMRC. S K was supported in part by the United States Department of Veterans Affairs.

\section{Author contribution statement}

A M, J G, T O, L M conceived and designed the study. M F, A M, L C, L P, J $G$, J $S$ performed study procedures. $M F$, J H, O H performed MRI fat quantification. M F, D S performed mathematical modelling. M F prepared figures and drafted the manuscript. $M F, A M, J G$ were involved in data analysis. M F, A M, J G, T O, S K, J H, D S, L G, L M, L K, L C, O H, J S read and edited the manuscript and approved the final version. M F, A M and J G are the guarantors of this work and, as such, has full access to all the data in the study and take responsibility for the integrity of the data and the accuracy of the data analysis.

\section{Acknowledgments}

The authors thank Nandipha Sinyanya, Ntombekhaya Zoneleni, Keitumetse Smouse and Hendriena Victor for their valuable contribution toward the study. Ali Alihumad from the MRC/UCT Medical Imaging Research Unit, Department of Human Biology, University of Cape Town, Cape Town, South Africa, are thanked for his assistance with obtaining the MRI scans.

\section{References}

1 Goedecke JH, Levitt NS, Lambert EV, Utzschneider KM, Faulenbach MV, Dave JA, West S, Victor H, Evans J, Olsson T et al. Differential effects of abdominal adipose tissue distribution on insulin sensitivity in black and white South African women. Obesity 200917 1506-1512. (https://doi.org/10.1038/oby.2009.73)

2 Keswell D, Tootla M \& Goedecke JH. Associations between body fat distribution, insulin resistance and dyslipidaemia in black and white South African women. Cardiovascular Journal of Africa 201627 177-183. (https://doi.org/10.5830/CVJA-2015-088)

3 Cnop M, Landchild MJ, Vidal J, Havel PJ, Knowles NG, Carr DR, Wang F, Hull RL, Boyko EJ, Retzlaff BM et al. The concurrent accumulation of intra-abdominal and subcutaneous fat explains the association between insulin resistance and plasma leptin concentrations: distinct metabolic effects of two fat compartments. Diabetes 200251 1005-1015. (https://doi.org/10.2337/ diabetes.51.4.1005)

4 Aasen G, Fagertun H \& Halse J. Regional fat mass by DXA: high leg fat mass attenuates the relative risk of insulin resistance and dyslipidaemia in obese but not in overweight postmenopausal women. Scandinavian Journal of Clinical and Laboratory Investigation 200868 204-211. (https://doi.org/10.1080/00365510701649524)

5 Goedecke JH, Keswell D, Weinreich C, Fan J, Hauksson J, Victor H, Utzschneider K, Levitt NS, Lambert EV, Kahn SE et al. Ethnic differences in hepatic and systemic insulin sensitivity and their associated determinants in obese black and white South African women. Diabetologia 201558 2647-2652. (https://doi.org/10.1007/ s00125-015-3720-7)

6 Piccinini F, Polidori DC, Gower BA \& Bergman RN. Hepatic but not extrahepatic insulin clearance is lower in African American than in European American women. Diabetes 201766 2564-2570. (https:// doi.org/10.2337/db17-0413)

7 Hakim O, Bello O, Bonadonna RC, Mohandas C, Shojaee-Moradie F, Jackson N, Boselli L, Whitcher B, Shuaib H, Alberti KGMM et al. Ethnic differences in intrahepatic lipid and its association with hepatic insulin sensitivity and insulin clearance between men of black and white ethnicity with early type 2 diabetes. Diabetes, Obesity and Metabolism 201921 2163-2168. (https://doi.org/10.1111/dom.13771)

8 Chung ST, Galvan-De La Cruz M, Aldana PC, Mabundo LS, DuBose CW, Onuzuruike AU, Walter M, Gharib AM, Courville AB, Sherman AS et al. Postprandial insulin response and clearance among black and white women: the federal women's study. Journal of Clinical Endocrinology and Metabolism 2019104 181-192. (https://doi. org/10.1210/jc.2018-01032)

9 Lingvay I, Mathur R, Szczepaniak EW \& Szczepaniak LS. Ethnic diversity in beta-cell function susceptibility to pancreatic 
triglyceride levels: pilot investigation. Journal of Diabetes and Metabolism 20145 348. (https://doi.org/10.4172/21556156.1000348)

10 Szczepaniak LS, Victor RG, Mathur R, Nelson MD, Szczepaniak EW, Tyer N, Chen I, Unger RH, Bergman RN \& Linvay I. Pancreatic steatosis and its relationship to $\beta$-cell dysfunction in humans: racial and ethnic variations. Diabetes Care 201235 2377-2383. (https://doi. org/10.2337/dc12-0701)

11 Pan XR, Li GW, Hu YH, Wang JX, Yang WY, An ZX, Hu ZX, Lin J, Xiao JZ, Cao HB et al. Effects of diet and exercise in preventing NIDDM in people with impaired glucose tolerance: the Da Qing IGT and diabetes study. Diabetes Care 199720 537-544. (https://doi. org/10.2337/diacare.20.4.537)

12 Trachta $\mathrm{P}$, Drápalová J, Kaválková $\mathrm{P}$, Toušková V, Cinkajzlová $\mathrm{A}$, Lacinová Z, Matoulek M, Zelinka T, Widimský Jr J, Mráz M et al. Three months of regular aerobic exercise in patients with obesity improve systemic subclinical inflammation without major influence on blood pressure and endocrine production of subcutaneous fat. Physiological Research 201463 (Supplement 2) S299-S308.

13 Bruce CR, Thrush AB, Mertz VA, Bezaire V, Chabowski A, Heigenhauser GJF \& Dyck DJ. Endurance training in obese humans improves glucose tolerance and mitochondrial fatty acid oxidation and alters muscle lipid content. American Journal of Physiology: Endocrinology and Metabolism 2006291 E99-E107. (https://doi. org/10.1152/ajpendo.00587.2005)

14 Dela F, Von Linstow ME, Mikines KJ \& Galbo H. Physical training may enhance $\beta$-cell function in type 2 diabetes. American Journal of Physiology: Endocrinology and Metabolism 2004287 E1024-E1031. (https://doi.org/10.1152/ajpendo.00056.2004)

15 Solomon TPJ, Sistrun SN, Krishnan RK, Del Aguila LF, Marchetti CM, O'Carroll SM, O'Leary VB \& Kirwan JP. Exercise and diet enhance fat oxidation and reduce insulin resistance in older obese adults. Journal of Applied Physiology 2008104 1313-1319. (https://doi.org/10.1152/ japplphysiol.00890.2007)

16 Johnson NA, Sachinwalla T, Walton DW, Smith K, Armstrong A, Thompson MW \& George J. Aerobic exercise training reduces hepatic and visceral lipids in obese individuals without weight loss. Hepatology 200950 1105-1112. (https://doi.org/10.1002/ hep.23129)

17 Heiskanen MA, Motiani KK, Mari A, Saunavaara V, Eskelinen JJ, Virtanen KA, Koivumäki M, Löyttyniemi E, Nuutila P, Kalliokoski KK et al. Exercise training decreases pancreatic fat content and improves beta cell function regardless of baseline glucose tolerance: a randomised controlled trial. Diabetologia 201861 1817-1828. (https://doi.org/10.1007/s00125-018-4627-x)

18 Goedecke JH, Mendham AE, Clamp L, Nono Nankam PA, Fortuin-de Smidt MC, Phiri L, Micklesfield LK, Keswell D, Woudberg NJ, Lecour $\mathrm{S}$ et al. An exercise intervention to unravel the mechanisms underlying insulin resistance in a cohort of black South African women: protocol for a randomized controlled trial and baseline characteristics of participants. JMIR Research Protocols 20187 e75. (https://doi.org/10.2196/resprot.9098)

19 Draper CE, Davidowitz KJ \& Goedecke JH. Perceptions relating to body size, weight loss and weight-loss interventions in black South African women: a qualitative study. Public Health Nutrition 201619 548-556. (https://doi.org/10.1017/S1368980015001688)

20 Goedecke JH, Micklesfield LK, Levitt NS, Lambert EV, West S, Maartens G \& Dave JA. Effect of different antiretroviral drug regimens on body fat distribution of HIV-infected South African women. AIDS Research and Human Retroviruses 201329 557-563. (https://doi.org/10.1089/aid.2012.0252)

21 Takagi S, Sakamoto S, Midorikawa T, Konishi M \& Katsumura T. Determination of the exercise intensity that elicits maximal fat oxidation in short-time testing. Journal of Sports Sciences 201432 175-182. (https://doi.org/10.1080/02640414.2013.815360)
22 Bergman RN, Ider YZ, Bowden CR \& Cobelli C. Quantitative estimation of insulin sensitivity. American Journal of Physiology 1979 236 E667-E677. (https://doi.org/10.1152/ajpendo.1979.236.6.E667)

23 Van Cauter E, Mestrez F, Sturis J \& Polonsky KS. Estimation of insulin secretion rates from C-peptide levels. Comparison of individual and standard kinetic parameters for C-peptide clearance. Diabetes 1992 41 368-377. (https://doi.org/10.2337/diab.41.3.368)

24 Polidori DC, Bergman RN, Chung ST \& Sumner AE. Hepatic and extrahepatic insulin clearance are differentially regulated: results from a novel model-based Analysis of Intravenous Glucose Tolerance Data. Diabetes 201665 1556-1564. (https://doi.org/10.2337/db151373)

25 Stefanovski D, Moate PJ \& Boston RC. WinSAAM: a windowsbased compartmental modeling system. Metabolism: Clinical and Experimental 200352 1153-1166. (https://doi.org/10.1016/s00260495(03)00144-6)

26 Burnham K \& Anderson D. Model Selection and Multimodel Inference: A Practical Information-Theoretic Approach, 2nd ed. New York: Springer, 2002.

27 Kovanlikaya A, Guclu C, Desai C, Becerra R \& Gilsanz V. Fat quantification using three-point Dixon technique: in vitro validation. Academic Radiology 200512 636-639. (https://doi. org/10.1016/j.acra.2005.01.019)

28 Al-Mrabeh A, Hollingsworth KG, Steven S, Tiniakos D \& Taylor R. Quantification of intrapancreatic fat in type 2 diabetes by MRI. PLOS ONE 201712 e0174660. (https://doi.org/10.1371/journal. pone.0174660)

29 Bonekamp S, Ghosh P, Crawford S, Solga SF, Horska A, Brancati FL, Diehl AM, Smith S \& Clark JM. Quantitative comparison and evaluation of software packages for assessment of abdominal adipose tissue distribution by magnetic resonance imaging. International Journal of Obesity 200832 100-111. (https://doi.org/10.1038/ sj.ijo.0803696)

30 Machann J, Bachmann OP, Brechtel K, Dahl DB, Wietek B, Klumpp B, Häring HU, Claussen CD, Jacob S \& Schick F. Lipid content in the musculature of the lower leg assessed by fat selective MRI: intra- and interindividual differences and correlation with anthropometric and metabolic data. Journal of Magnetic Resonance Imaging 200317 350-357. (https://doi.org/10.1002/jmri.10255)

31 Hakim O, Bonadonna RC, Mohandas C, Billoo Z, Sunderland A, Boselli L, Alberti KGMM, Peacock JL, Umpleby AM, CharlesEdwards $\mathrm{G}$ et al. Associations between pancreatic lipids and $\beta$-cell function in black African and white European men with type 2 diabetes. Journal of Clinical Endocrinology and Metabolism 2019104 1201-1210. (https://doi.org/10.1210/jc.2018-01809)

32 Shen W, Chen J, Gantz M, Velasquez G, Punyanitya M \& Heymsfield SB. A single MRI slice does not accurately predict visceral and subcutaneous adipose tissue changes during weight loss. Obesity 201220 2458-2463. (https://doi.org/10.1038/ oby.2012.168)

33 Procter AJ, Sun JY, Malcolm PN \& Toms AP. Measuring liver fat fraction with complex-based chemical shift MRI: the effect of simplified sampling protocols on accuracy. BMC Medical Imaging 201919 14. (https://doi.org/10.1186/s12880-019-0311-y)

34 Alizai H, Nardo L, Karampinos DC, Joseph GB, Yap SP, Baum T, Krug R, Majumdar S \& Link TM. Comparison of clinical semiquantitative assessment of muscle fat infiltration with quantitative assessment using chemical shift-based water/fat separation in MR studies of the calf of post-menopausal women. European Radiology 201222 1592-1600. (https://doi.org/10.1007/s00330-012-2404-7)

35 Nordby P, Auerbach PL, Rosenkilde M, Kristiansen L, Thomasen JR, Rygaard L, Groth R, Brandt N, Helge JW, Richter EA et al. Endurance training per se increases metabolic health in young, moderately overweight men. Obesity 201220 2202-2212. (https://doi. org/10.1038/oby.2012.70) 
36 Goedecke JH, Dave JA, Faulenbach MV, Utzschneider KM, Lambert EV, West S, Collins M, Olsson T, Walker BR, Seckl JR et al. Insulin response in relation to insulin sensitivity: an appropriate beta-cell response in black South African women. Diabetes Care 2009 32 860-865. (https://doi.org/10.2337/dc08-2048)

37 Chow CC, Periwal V, Csako G, Ricks M, Courville AB, Miller BV, Vega GL \& Sumner AE. Higher acute insulin response to glucose may determine greater free fatty acid clearance in African-American women. Journal of Clinical Endocrinology and Metabolism 201196 2456-2463. (https://doi.org/10.1210/jc.2011-0532)

38 Brown MD, Moore GE, Korytkowski MT, McCole SD \& Hagberg JM. Improvement of insulin sensitivity by short-term exercise training in hypertensive African American women. Hypertension 199730 1549-1553. (https://doi.org/10.1161/01.HYP.30.6.1549)

39 Many G, Hurtado ME, Tanner C, Houmard J, Gordish-Dressman H, Park JJ, Uwaifo G, Kraus W, Hagberg J \& Hoffman E. Moderateintensity aerobic training program improves insulin sensitivity and inflammatory markers in a pilot study of morbidly obese minority teens. Pediatric Exercise Science 201325 12-26. (https://doi. org/10.1123/pes.25.1.12)

40 King DS, Baldus PJ, Sharp RL, Kesl LD, Feltmeyer TL \& Riddle MS. Time course for exercise-induced alterations in insulin action and glucose tolerance in middle-aged people. Journal of Applied Physiology 199578 17-22. (https://doi.org/10.1152/jappl.1995.78.1.17)

41 Racil G, Ben Ounis O, Hammouda O, Kallel A, Zouhal H, Chamari K $\&$ Amri M. Effects of high vs. moderate exercise intensity during interval training on lipids and adiponectin levels in obese young females. European Journal of Applied Physiology 2013113 2531-2540. (https://doi.org/10.1007/s00421-013-2689-5)

42 AbouAssi H, Slentz CA, Mikus CR, Tanner CJ, Bateman LA, Willis LH, Shields AT, Piner LW, Penry LE, Kraus EA et al. The effects of aerobic, resistance, and combination training on insulin sensitivity and secretion in overweight adults from STRRIDE AT/RT: a randomized trial. Journal of Applied Physiology 2015118 1474-1482. (https://doi. org/10.1152/japplphysiol.00509.2014)

43 Short KR, Vittone JL, Bigelow ML, Proctor DN, Rizza RA, CoenenSchimke JM \& Nair KS. Impact of aerobic exercise training on age-related changes in insulin sensitivity and muscle oxidative capacity. Diabetes 200352 1888-1896. (https://doi.org/10.2337/ diabetes.52.8.1888)

44 Samjoo IA, Safdar A, Hamadeh MJ, Raha S \& Tarnopolsky MA. The effect of endurance exercise on both skeletal muscle and systemic oxidative stress in previously sedentary obese men. Nutrition and Diabetes 20133 e88. (https://doi.org/10.1038/nutd.2013.30)

45 Shojaee-Moradie F, Baynes KC, Pentecost C, Bell JD, Thomas EL, Jackson NC, Stolinski M, Whyte M, Lovell D, Bowes SB et al. Exercise training reduces fatty acid availability and improves the insulin sensitivity of glucose metabolism. Diabetologia $2007 \mathbf{5 0} 404-413$. (https://doi.org/10.1007/s00125-006-0498-7)

46 Kahn SE, Larson VG, Schwartz RS, Beard JC, Cain KC, Fellingham GW, Stratton JR, Cerqueira MD \& Abrass IB. Exercise training delineates the importance of B-cell dysfunction to the glucose intolerance of human aging. Journal of Clinical Endocrinology and Metabolism $19927 \mathbf{7 4}$ 1336-1342. (https://doi.org/10.1210/jcem.74.6.1592879)

47 Slentz CA, Tanner CJ, Bateman LA, Durheim MT, Huffman KM, Houmard JA \& Kraus WE. Effects of exercise training intensity on pancreatic B-cell function. Diabetes Care 200932 1807-1811. (https://doi.org/10.2337/dc09-0032)
48 Solomon TPJ, Malin SK, Karstoft K, Kashyap SR, Haus JM \& Kirwan JP. Pancreatic $\beta$-cell function is a stronger predictor of changes in glycemic control after an aerobic exercise intervention than insulin sensitivity. Journal of Clinical Endocrinology and Metabolism 201398 4176-4186. (https://doi.org/10.1210/jc.2013-2232)

49 Malin SK, Solomon TPJ, Blaszczak A, Finnegan S, Filion J \& Kirwan JP. Pancreatic $\beta$-cell function increases in a linear dose-response manner following exercise training in adults with prediabetes. American Journal of Physiology: Endocrinology and Metabolism $2013 \mathbf{3 0 5}$ E1248-E1254. (https://doi.org/10.1152/ajpendo.00260.2013)

50 West DS, Elaine Prewitt T, Bursac Z \& Felix HC. Weight loss of black, white, and hispanic men and women in the diabetes prevention program. Obesity 200816 1413-1420. (https://doi.org/10.1038/ oby.2008.224)

51 Polak J, Bajzova M \& Stich V. Effect of exercise on lipolysis in adipose tissue. Future Lipidology 20083 557-572. (https://doi. org/10.2217/17460875.3.5.557)

52 Gower BA \& Goss AM. A lower-carbohydrate, higher-fat diet reduces abdominal and intermuscular fat and increases insulin sensitivity in adults at risk of type 2 diabetes. Journal of Nutrition 2015145 177S-183S. (https://doi.org/10.3945/jn.114.195065)

53 Kahn SE, Prigeon RL, McCulloch DK, Boyko EJ, Bergman RN, Schwartz MW, Neifing JL, Ward WK, Beard JC \& Palmer JP. Quantification of the relationship between insulin sensitivity and beta-cell function in human subjects. Evidence for a hyperbolic function. Diabetes 199342 1663-1672. (https://doi.org/10.2337/ diab.42.11.1663)

54 Kodama K, Tojjar D, Yamada S, Toda K, Patel CJ \& Butte AJ. Ethnic differences in the relationship between insulin sensitivity and insulin response: a systematic review and meta-analysis. Diabetes Care 2013 36 1789-1796. (https://doi.org/10.2337/dc12-1235)

55 Piccinini F, Polidori DC, Gower BA, Fernandez JR \& Bergman RN. Dissection of hepatic versus extra-hepatic insulin clearance: ethnic differences in childhood. Diabetes, Obesity and Metabolism 201820 2869-2875. (https://doi.org/10.1111/dom.13471)

56 Gavin JR, Roth J, Neville DM, de Meyts P \& Buell DN. Insulin dependent regulation of insulin receptor concentrations: a direct demonstration in cell culture. PNAS 197471 84-88. (https://doi. org/10.1073/pnas.71.1.84)

57 Templeman NM, Skovsø S, Page MM, Lim GE \& Johnson JD. A causal role for hyperinsulinemia in obesity. Journal of Endocrinology 2017 232 R173-R183. (https://doi.org/10.1530/JOE-16-0449)

58 Goedecke JH, Evans J, Keswell D, Stimson RH, Livingstone DEW, Hayes P, Adams K, Dave JA, Victor H, Levitt NS et al. Reduced gluteal expression of adipogenic and lipogenic genes in black South African women is associated with obesity-related insulin resistance. Journal of Clinical Endocrinology and Metabolism 201196 E2029-E2033. (https:// doi.org/10.1210/jc.2011-1576)

59 Evans J \& Goedecke JH. Inflammation in relation to cardiovascular disease risk: comparison of black and white women in the United States, United Kingdom, and South Africa. Current Cardiovascular Risk Reports 20115 223-229. (https://doi.org/10.1007/s12170-0110168-2)

60 Kotzé-Hörstmann LM, Keswell D, Adams K, Dlamini T \& Goedecke JH. Hypoxia and extra-cellular matrix gene expression in adipose tissue associates with reduced insulin sensitivity in black South African women. Endocrine 201755 144-152. (https://doi. org/10.1007/s12020-016-1089-0)

Received 21 November 2019

Revised version received 17 April 2020

Accepted 29 April 2020 